\title{
Research on Precise Marketing Strategy of Commercial Bank against the Background of Internet Finance
}

\author{
Xuehong Zhao* \\ School of Management \\ Harbin Finance University \\ Harbin, China \\ 23212949@qq.com
}

\author{
Zhaoqi Liu \\ School of Management \\ Harbin Finance University \\ Harbin, China \\ sunshoone@126.com
}

\begin{abstract}
The traditional marketing methods haven't been able to satisfy the consumers' need in the increasingly fierce marketing competition. The precise marketing realized the implementation of customer flexible management by data mining, and then improved the marketing efficiency of the company. Based on the exploration of the related concepts and the deeply analysis of the influence of internet finance on the marketing of commercial banks, this paper puts forward the precise marketing strategy of commercial banks from four aspects, which include customer requirements analysis, market segmentation and position, marketing combination and marketing control and assessment. This paper also helps commercial bank marketing management transfer to the precise marketing and provides a new way of thinking for innovation and development. Only by considering the customers, markets, products, services and other elements in the context of internet finance and delivering products or services to customers differently, and establishing a differentiated brand image in the heart of the customer, can commercial banks win the competition or even lead the trend in the intelligent age.
\end{abstract}

Keywords-commercial bank; precise marketing; internet finance; marketing strategy

\section{INTRODUCTION}

Internet finance began with the information revolution and the big data era which has been developed very fast since 2013 With the advantage of information technology, it showed strong innovation and competitiveness. Its specific advantage triggered the entire financial industry innovation to a certain extent. Commercial banks, as an important part of the financial system, are impacted more seriously and directly. Its market pattern and development mode have even been changed by the internet finance. How to take positive and effective measures to deal with the circumstance will directly affect the survival and development of commercial banks in the internet finance context. Marketing is considered as the main position of the internet financial practice. Against the background of internet finance, commercial banks marketing become an interdisciplinary subject of economic management, science, and technology, psychology, which guides

This research was supported by Youth Innovative Talents Training Project of Harbin Finance University in 2016 (E052016001), Harbin Finance University important subject in 2017 (E012017006) and The basic research fee project of Heilongjiang provincial universities in 2017(2017-KYYWF0083). commercial banks to improve market efficiency. With the help of the large data mining technology, precise marketing analysis massive data, which can position the customer's demand precisely, and realize the aim of selling the right products to the right people in the right place. Precise marketing provides a new way of thinking for commercial banks innovating marketing strategy in the context of the internet finance.

\section{INTERNET FINANCE, BIG DATA ANALYSIS, AND PRECISE} MARKETING

\section{A. Internet Finance}

Internet Finance, which emphasizes data-driven operation, generally refers to all behaviors achieving financing by internet technology. It mainly relies on data mining, cloud computing, mobile payment and other internet tools to realize financing, payment and information intermediary. Its core values are "open, equal, collaborative, and shared"; it also emphasizes the business philosophy of "customer-centered" and "customer experience". Internet finance is overall changing the picture of the traditional banking industry chain through the gradual reconstruction of the market, customers, products and value chain.

\section{B. Big Data Analysis}

Banking is a business that is destined to have massive amounts of data. With the popularization and progress of information technology, data collection and use have been referred to the strategic height. How to collect, save, maintain, manage, analyze, and share data is growing exponentially an important challenge we must face. The significance of big data lies in: humans can analysis and the use of data in a large increase, through the exchange, integration and analysis of these data, human can discover new knowledge and create new value, such as "great knowledge", "big science", "big profits" and "great development". More importantly, with the rapid increase of big data, people are trying to use data to make decisions, manage with data and innovate with data. The realization of precise marketing through data mining is one of the meanings of big data. A large number of data is automatically analyzed through a specific algorithm, which 
can reveal hidden historical laws and future trends in data, and provide policy reference for decision makers.

\section{Precise Marketing}

The precise marketing concept is proposed by professor Philip Kotler, the father of marketing[1]. The precise marketing is the establishment of personalized customer communication service system, which bases on the precise position of customers, and relies on the information systems of the data analysis. The core idea of precise marketing lies in precise, that is, for the target customers, to take more precise marketing methods to obtain measurable marketing results. Precise marketing establishes a personalized marketing program through precisely evaluating of a series of factors on the marketing chain and precisely positioning and data analysis. With precise measures that can be manipulated and evaluated, it strives to reflect precisely the marketing process and realizes the precise customer marketing. Compared with the traditional marketing, precise marketing pays more attention to the effective success rate of business activities[2].

\section{The IMPACT OF INTERNET FinANCE ON COMMERCIAL}

\section{BANK MARKETING}

With the rapid development of internet finance, commercial banks' core business has been impacted disruptively, systematically and persistently, and its profitability has also been seriously impacted. Commercial banks not only need to face the challenges which brought about by the internet finance, but also need to analyze their own situation objectively and rationally, and at the same time, it should seize the opportunity of the rapid development of the internet.

They should guide the customers to pay more attention to efficiency and cost with its own unique advantages. And the most important is that they should pay more attention to the customer experience and provide customers with a variety of financial products, services, and personalized service. The influence of internet finance on the commercial banks marketing mainly lies in the following aspects:

\section{A. Customer-Centered}

The essence of internet finance is customer-centered, its product design and business practice are all processed according to the customer's needs. Internet finance management idea pays attention to two aspects: it emphases to improving itself, and at the same time focusing on customer's experience and the customer loyalty training. The business model and management concept of commercial banks turn from "account-centered" to "customer-centered" . At the same time, it pays attention to the individual groups of consumers. Internet finance makes the market structure upgrade to the buyer's market. Commercial bank, as a seller, needs further attention to individual consumer in the marketing activities.

\section{B. Financial Service Disintermediation}

Disintermediation generally refers to the transaction occurred directly between the supply and demand sides and skip all intermediary. In the traditional financial system, the payment and settlement must be realized through the commercial bank. But in the internet finance era, the development of third-party payment companies realizes a certain degree of financial service disintermediation by internet technology, and this makes the traditional commercial bank business suffer the dramatic impact. Commercial banks must change the traditional marketing model, make full use of big data technology, and strive for the maximum value by the lowest cost.

\section{Marketing Environment Virtualization}

Traditional marketing of commercial banks is mainly through offline publicity and promotion by the customer manager and media advertising. With the overall development of internet finance, internet financial enterprises have broken the barriers to the entry of commercial banks and can complete network marketing without any physical network. Customers can choose their satisfactory bank products provided by the internet financial enterprises platform, and complete their payment at home through Alipay, WeChat payment, fast payment and other convenient ways, and these help the customers develop gradually new financial consumption habits during the process of experience, which requires the commercial banks to pay more attention to the construction of virtual marketing channels while paying attention to the traditional marketing channels.

\section{Marketing Decision Data-Based}

Scientific decisions require a certain amount of information to support, and most of the information comes from data or hide in data. The whole marketing process cannot be separated from the data, and the correct use of the data often determines the actual effect of marketing. Against the background of financial disintermediation, the functions of intermediary in bank funds will significantly weaken, and the information intermediary functions will continue to strengthen, data has become the bank's core assets, and the ability of data utilization will become one of the core competitiveness. Commercial banks should have the consciousness of relying on data decision-making, change the traditional way of implementing management by intuitive feelings, experience judgment, and assist the management decision by data analysis[3].

\section{The Precise Marketing Strategy of Commercial BANKS}

Marketing plays an important role in the commercial bank business process. Under the changing marketing environment, to keep in insight into consumer's behavior and to develop precise marketing strategy become the first problem for commercial banks to consider in the marketing process. For commercial banks, first of all, they should have a clear selfawareness; secondly, they should have an overall master for the needs of the users, and understand their idea and behavior; finally, improve the commercial bank's marketing efficiency and competitive ability by the implementation of precise marketing strategy. 


\section{A. Exact Customer Requirements Analysis}

In the internet finance era, it is possible to collect and store huge amounts of data. Making full use of the data information and building the information system, which can satisfy the requirements of data storage, analysis and retrieval are realistic problems that commercial banks must face and solve. All customers' information can be restored from the data, and commercial banks can even better understand customers' needs than themselves with the help of the big data.

The research on the commercial bank's products should take into account the customers' needs from the beginning of conception. Only when the financial products satisfy the personalized customers' needs efficiently and innovate and launch product services quickly, can commercial banks keep their advantages in long-term competition. Commercial banks should establish a big customer data information platform center that can be shared by various branches and each branch should also collect customer information from the grassroots and collect it to the big data platform center.

Big data information platform should carry out depth mining and statistical analysis of customer data information and primary database information which grabs from a variety of channels. Commercial banks should explore effective ways to capture and filter information on the internet, obtain effective information through the third party data service provider and improve the technical level of dealing with broken data. Based on the integration of the structured and unstructured data resource, commercial banks can depict customer portrait completely, calculate the customer's risk preferences, consumption habits, hobbies and other personal information, and find the marketing point, discover customer needs, and then the commercial bank is most likely to push customers the financial products and services that meet customer demand according to the results of the analysis, so as to fulfill the differentiated marketing. [4].

\section{B. Precise Market Segmentation and Position}

Precise market segmentation and position are to make the product or service image of commercial banks occupy a strong position in the customers' minds. When the customers have the relevant needs, they can immediately think of the product and service, and make purchase decisions. Against the background of internet finance, precise marketing requires commercial banks the refinement of the market segmentation using the big data. Commercial banks should implement market segmentation by the clustering analysis, factor analysis, association rules, correspondence analysis, regression analysis, variance analysis, decision tree and collaborative filtering method. The use of advanced data analysis technology is to realize customer segmentation, so as to provide targeted marketing services for customers. By the use of these technologies, commercial banks can understand the characteristics of the target customer, divide the target customer group into different groups, judge the model of consumer behavior and value of the target group and further subdivision, and distinguish the loyal customers and general customers. On the basis of above, commercial banks analysis the target consumer' demand and preference and guide their market position activities which will carry out subsequently.
In the evaluation of different market segments, commercial banks need to pay attention to two points: first, the commercial bank must consider all kinds of market segments, such as economy scale, risk factors, growth situation; second, the commercial bank must consider that if the market segments of the investment's goal and commercial banks' are the same. If commercial banks want to realize effectively grasp of the market segments and to have a dominant position in the fierce market competition, they do not only need to have enough customers, but also need to achieve precise position of customers, provide personalized service to different customer, and promote the marketing strategy to be more targeted by the variety development. The key to the position is to integrate the customer data from multiple angles through the integration of multiple information channels. Commercial banks establish service files for customers, and with the statistical analysis of data, provide the appropriate service and product combination scheme for customers.

Commercial banks should understand customer's needs according to their risk tolerance, the cognitive ability for the new things and the service satisfaction. They also collect the spending habits, investment philosophy and preference behavior, guide and dig out the customer internal financial consumer demand[5].

Through precise position of users, commercial banks marketing become more targeted and clearer purpose, and this helps greatly reduce the overall marketing cost of commercial banks[6].

\section{Fine Marketing Combination}

According to the characteristics and preferences of different customer groups, commercial banks should build a precise marketing combination, use comprehensively the personalized product strategy, price strategy, channel combination strategy, promotion strategy to achieve precise marketing.

(1) Product strategy. Based on a variety of structured and unstructured data and customer related data analysis, commercial banks can find out the laws and potential model, combine with the characteristics of the customers, extrapolate and predict the development of things, focus on increasing customer value. After customers subdivision, commercial banks can design different products belong to the customer group according to different customer label. After the depth analysis of the target customer needs, commercial banks should find the relationship among the various labels, so that the attributes of the product can fit the needs of customers as much as possible, compose the best product collocation for customers, and stimulate effectively the customer's desire to buy. On the one hand, customers can experience the personalized products; on the other hand, commercial banks can also compose effectively various marketing products.

(2) Price strategy. Against the internet finance background, commercial banks are not pricing blindly, they need to fully collect consumer demand data, measure competitors' pricing factors, then carry out the differential pricing according to the analysis of the commercial bank target profit and cost. 
(3) Channel strategy. The progress of science and technology makes more and more customers tend to meet their needs by the network channels as their first choice, tend to buy the products they need on the internet and only treat the store as the exhibition platform. The key competition strategy of banks is to create and transfer of customer value. Only when commercial banks are close to the customer's value demand, can they have the market competitiveness. Create the physical channel to be a platform for customer counseling, communication and customer experience interactive sites, strengthen self-help intelligence channel construction, promote business linkage processing, achieve the depth integration of online and offline channel and form a benign interaction.

(4) Promotion strategy. Communication is the essence of promotion. In big data era, customers are increasingly involved in the process of creating value, and they become the core value creation. Commercial banks should communicate with customers according to their behavioral characteristics and personality preferences, impress those customers who have obvious consumption characteristics through customer's data collection, analysis consumers' individual demand.

With the help of Email, SNS, network account and DSP, commercial banks adopt personalization push technology, which based on the method, the platform, the content, to recommend product or service in personalization, help the customers avoiding browse a lot of useless information, so as to reduce customer churn.

Commercial banks allow customers to participate personally in the production and the designation of the product, so as to achieve comprehensive customization needs of customers. User experience is the subjective feeling that constructs in the process when the customers purchase or use the products, which determines whether customers will continue to buy products and become commercial banks' loyal customers. Commercial banks should find out the most concern and care factors of customers, provide corresponding improvement and service for these factors, and improve user experience and customer satisfaction[7].

\section{Accurate Marketing Control and Assessment}

Commercial banks should construct precise marketing control and assessment system, adopt effective monitoring means and customer information feedback mechanism and adjust strategy timely. Before customers purchase products or services, commercial banks should hold various user experience activities. In the process of experience, they provide one to one experience service to the select precise customers and cultivate customer's consumption habits and dependence path. When customers choose commercial banks' products, commercial banks should help customers feel the value added, so that they can find the balance point between service level and the price they paid. When commercial banks have completed a service for a customer, they should establish a complete after-sale service system, and improve customer satisfaction by perfect after-sale service. Commercial banks should respond to the customer's evaluation in time. Through real-time, interactive dialogue, they guide the customers to send positive information about the products or services, so as to improve the service quality.

They should guide the public opinion by using reputation to influence customers. It will not only help to improve the commercial banks' brand image, but also enhance the customer' presence sense and the perception of brand and service, thus they become loyal customers. Commercial banks should establish a perfect customers lifetime evaluation system for them, analyze the relevant customers' information, test the quality of information, and integrate the data of the system, conduct quantitative analysis on the basis of the qualitative analysis, and predict the customer's behavior[8].

\section{SuMmary}

This paper takes commercial bank's precise marketing as the research object against the background of internet finance, the main results are as follows:

First, against the background of internet finance, with the help of big data mining technology, it is possible for commercial banks to carry out accurate marketing.

Second, the impacts of internet finance on the marketing of commercial banks are mainly reflected in customer-centered, financial service disintermediation, marketing environment virtualization and marketing decision data-based.

Third, we put forward "four-precise" marketing strategies of commercial banks against the background of internet finance, which includes exact customer requirements analysis, precise market segmentation and position, fine marketing combination and accurate marketing control and assessment.

Commercial banks as an important part of the financial system, play key roles in the development of the financial industry and the whole national economy. They must change their development strategies, formulate new marketing strategies actively, carry out marketing activities effectively, increase marketing share and promote profit growth.

\section{REFERENCES}

[1] Gong Min, Liu Guangdan. An overview of application research Based on Big Data[J]. Market Weekly, 2016(7):58-60. (In Chinese)

[2] Lin Qingpeng. The Research of Precise Marketing Strategy Based on Big Data Mining[D]. Lanzhou, Lan zhou University of Technology, 2016, 13-15. (In Chinese)

[3] Chen Tao. Research on CITIC Bank Network Marketing Strategies under the Internet Financial Environment[D]. Hefei, Anhui University, 2016, 14-17. (In Chinese)

[4] http://www.ebrun.com/20170622/236214.shtml

[5] Liu Hai, Luhui, Ruan Jinhua, Tian Bingqiang, Hu Shouzhong. Research on Precise Marketing Segmentation Model Based on Mining "Persona" [J]. Journal of Silk, 2015(12), 37-42. (In Chinese)

[6] Huang Shengmin, Liu Shan. Deconstruction and reconstruction of the marketing system against the background of big data[J]. Modern Communcation, 2012(11):13-20. (In Chinese)

[7] Zhang Yang. The Marketing Strategy Analysis of Commercial Banking in the Big Data Era - Taking the Bank of China as An Example[D]. Baoding, Hebei Finance University, 2016, 28-30. (In Chinese)

[8] http://theory.people.com.cn/n/2014/0811/c40531-25441383.html 